\title{
ANÁLISE DA PRODUÇÃO CIENTÍFICA SOBRE A AFETIVIDADE NA EDUCAÇÃO
}

\author{
Kátia Cardoso Campos Simonetto ${ }^{1}$ Adriano.Ruiz ${ }^{2}$ Camélia Santina Murgo ${ }^{3}$ \\ ${ }_{1}^{1}$ Discente do Programa de Mestrado em Educação - UNOESTE. ${ }^{2}$ Docente do Programa de Mestrado em Educação - UNOESTE, \\ ${ }^{3}$ Docente do Curso de Psicologia - UNOESTE. E-mail: katia@utfpr.edu.br
}

\section{RESUMO}

O presente trabalho objetivou a realização de um levantamento da literatura científica, publicada em bases de dados de periódicos científicos, a respeito da afetividade na educação. Para desenvolver este estudo a metodologia utilizada foi à pesquisa bibliográfica com revisão sistemática. Para tanto, foi realizada uma busca nas bases e livros em agosto de 2012, a partir de critérios de seleção e exclusão e termos definidos a priori, tendo como escopo de análise um total de 09 artigos que tiveram seus textos analisados. Os dados coletados foram de participantes provenientes dos estados de São Paulo (5 artigos), Pernambuco (2 artigos) e Bahia (2 artigos). Pretende-se com este estudo contribuir para novas pesquisas sobre 0 assunto.

Palavras-chave: Desenvolvimento. Afetividade. Educação.

\section{SCIENTIFIC ANALYSIS OF PRODUCTION ON EDUCATION IN AFFECTIVITY}

\begin{abstract}
ABSTRAT
This study aimed to conduct a survey of the scientific literature published in databases of scientific journals regarding the affectivity in education. To develop this study, the methodology used was the literature research with systematic review. Therefore, we performed a search on the bases and books in August 2012, from selection and exclusion criteria and terms defined a priori, with the scope of analysis a total of 09 articles that had their texts analyzed. The data were collected from participants from the states of São Paulo (5 items), Pernambuco (2 articles) and Bahia (2 articles). The aim of this study contribute to further research on the subject.

Keywords: Development. Affectivity. Education.
\end{abstract}




\section{INTRODUÇÃO}

A afetividade é um fator que pode influenciar a vida de todo ser humano nas diversas esferas nas quais está inserido (SILVA; SHNEIDER, 2009;GOTTMAN, 1997). Buscar embasamento teórico para a compreensão da vida familiar, das relações sociais, bem como da educação escolar formal é de importância ímpar para a compreensão do quanto e como a afetividade influencia a vida dos indivíduos.

Para discutir os artigos da pesquisa citamos Wallon como um dos maiores pesquisadores da afetividade. Ele é o referencial teórico mais citado nesta análise. Segundo Wallon (2007), a afetividade é de extrema importância para a constituição e 0 funcionamento da inteligência determinando os interesses e as necessidades individuais.

Em relação a afetividade no contexto escolar, estudos vêm apontando o entrelaçamento entre afetividade, aprendizagem $e$ ensino com isso trazendo argumentos que defendem que amor, carinho, respeito, afeto, solidariedade, e companheirismo são alguns dos sentimentos que deve haver entre alunos e professores, para que esses alunos possam crescer em um ambiente saudável e se desenvolverem. O desenvolvimento afetivo depende, dentre outros fatores, da qualidade dos estímulos e do meio em que se vive, para que satisfaçam as necessidades básicas de afeto, apego, segurança, disciplina e comunicação, pois é nessas situações que a criança estabelece vínculos com outras pessoas (SILVA; SCHNEIDER, 2007).

A escola exerce influência na vida do aluno, pois proporciona a atualização dos conhecimentos básicos adquiridos em família e também desenvolve novos sentimentos e novas experiências preparando a criança para se adequar a sociedade incorporando sentimentos e garantindo a compreensão do que é viver em sociedade. É preciso dar a devida importância aos primeiros contatos da criança com a escola, é necessário que a criança seja bem recebida, pois neste momento ela está rompendo os laços familiares e iniciando uma experiência, a partir daí a criança conhecerá os novos sentimentos que envolvem a afetividade, sentimentos diferentes dos que sente pelos pais, irmãos e parentes, essa nova experiência deve ser bem sucedida, prazerosa, pois quando a criança percebe que o professor tem paciência, dedicação e que gosta dela, o aprendizado torna-se mais fácil porque o aluno se sente motivado e interessado em aprender, acaba gostando e confiando no professor, passa a respeitá-lo por sentimentos e não por imposições (ANTUNES, 2008).

Por esses motivos deve-se trabalhar a afetividade em sala de aula e o professor deve entender que o ensino não deve ser somente a transferência do saber e sim o desenvolvimento de uma relação de amizade em que possa observar os problemas encontrados em sala de aula, os sentimentos de cada aluno, e ajudá-los a buscar soluções, criando, assim, também seu caráter. Assim, a relação afetiva entre professor e aluno, influenciará também, no processo de ensino-aprendizagem.

Conforme Vigotsky (1999) descreve a aprendizagem estará comprometida, pois emoções implicam diretamente na atividade intelectual do aluno. Não conseguimos controlar nossos atos quando estamos muito afetados por algo. Na concepção do mesmo autor, ao falar da importância das relações interativas sociais é necessário também ser considerada a ideia da mediação e da internalização como fundamental para a aprendizagem. Ele defende que é nas interações sociais que ocorre a construção do conhecimento. Então as crianças precisam da interação com outras pessoas para se 
desenvolverem. A criança vai também construindo seu próprio sujeito e sua forma de agir. O papel do outro se torna fundamental no processo de aprendizagem (VYGOSTSKY, 1984).

Além do contato com o professor, também existe o contato com os outros alunos que proporcionará 0 inicio do convívio na sociedade, que ensinará o respeito, a admiração e a partilha. Os alunos passarão a criar seus próprios grupos, respeitando regras, buscando colegas que tenham a mesma personalidade $e$ assim conhecendo as personalidades de outros colegas, convivendo com diferentes culturas, percebendo que é necessário o respeito acima de tudo para que possam conviver tranquilamente, experimentando novos sentimentos, desenvolvendo sua inteligência, experiências essas que não são possíveis no âmbito familiar (LEITE, 2006).

Um estudo a cerca da afetividade foi desenvolvido por Ribeiro et al. (2005) no qual relata que a forma como os professores representam a competência afetiva na relação educativa determina a importância que eles dão aos diferentes elementos que compõem tal competência e também destaca a organização do conteúdo das representações de afetividade. Observou-se que os professores entendem a afetividade como um sentimento que é concebido através da afeição entre os indivíduos e que este sentimento é adquirido através de atitudes internas que levam o aluno a respeitar, proteger, ajudar, compreender e desejar a aproximação do outro.

Também foi observado que a relação de afetividade fortalece $\mathrm{o}$ vinculo entre alunos e professores e em um ambiente de confiança, os alunos passam a construir uma autoimagem positiva, um compromisso com o professor e passam a participar ativamente das aulas melhorando a qualidade do ensino e diminuindo a desistência nos estudos (RIBEIRO et al., 2005).
Ribeiro (2005) através de entrevistas com professores constatou que os programas de formação de docente são falhos no que diz respeito ao universo da afetividade. Falta orientação, sugestões e auxilio na hora de resolver situações com alunos que trazem consigo problemas graves. Um professor afetivo tem algumas características que são: ser humano, seguro, afetuoso, compreensivo, humilde, confiante, próximo, e aberto às criticas e ao diálogo. Ele deve estar atento às necessidades dos alunos, estar disponível para conversas, deve ser criativo, trazendo a teoria para o cotidiano dos alunos, estimular a prática de trabalhos em grupo, observar as mudanças que ocorrem em seus alunos e estar em constante busca pelo saber, adquirindo conhecimentos.

O desenvolvimento do respeito e da confiança entre professor-aluno e de aluno-aluno faz com que cada indivíduo aprenda a expressar seus sentimentos de forma natural e assim o professor passa a observar e conhecer as dificuldades dos seus alunos. Neste processo de conhecimento destaca-se que é importante observar os obstáculos que existem nesta busca pela afetividade aluno-professor. Alguns dos obstáculos encontrados são: os comportamentos indesejáveis dos alunos, o meio em que vivem a miséria, promiscuidade e carência afetiva familiar. $E$ também as condições pessoais e profissionais dos professores, que é importante frisarem que são seres humanos e têm suas dificuldades e limitações como: as frustrações pessoais e profissionais, a baixa estima, o salário insuficiente, a não valorização do trabalho social que eles desempenham a falta de apoio das próprias famílias dos alunos que por muitas vezes acabam tirando a autoridade do professor, o medo de perder o controle na sala de aula que gera atitudes por parte dos professores que são nocivas a afetividade (RIBEIRO, 2005). 
Souza apud Witter (2004) também destaca em seu estudo a importância da visão positiva do professor em relação a si mesmo, sua valorização, acreditar em si mesmo. Como a função do professor é, além de transmitir o conhecimento, formar adultos pensantes, com caráter, com dignidade, ajudá-los a progredir, dar carinho e atenção que muitas vezes não recebem de suas famílias, os professores precisam estar bem consigo mesmo, ter autoestima, precisam ser valorizados e respeitados, precisam ter orientação para saber como agir e como planejar atividades dinâmicas para aproximar os alunos e poder assim observá-los em momentos de descontração.

Fica destacada pelos estudiosos aqui referendados a necessidade de se cuidar do aspecto afetivo no processo ensinoaprendizagem, levando em conta cada fase do desenvolvimento humano $o$ que justifica 0 objetivo desse estudo, a saber, realizar um levantamento na literatura científica a respeito da afetividade na educação.

\section{METODOLOGIA}

Esta investigação trata de uma revisão sistemática, onde se buscou subsídios nos artigos científicos que tratavam sobre a afetividade no contexto da educação. Estes artigos foram publicados entre os anos de 2005 e 2010. Foi feita uma busca em bases de dados eletrônicos brasileiros, que agrupam grande parte das revistas científicas da área da educação, que são PePSIC e Scielo, no mês de agosto de 2012. Nessas bases, foram usados os seguintes termos para busca dos artigos: Afetividade, Afetividade e Educação, Desenvolvimento da afetividade, Afetividade na escola, Afetividade na relação professor e aluno.
Assim, um total de nove artigos cumpriu a todos os critérios. As informações foram buscadas nos resumos e quando não foi possível encontrá-las, procedeu-se a consulta ao texto completo. Foram analisados e comparados todos os artigos selecionados.-As variáveis investigadas foram quantidade de autores, instituições e estados de origem dos autores, tipos de pesquisa e análises de dados utilizadas.

\section{RESULTADOS}

Os resultados serão apresentados em dois blocos. Inicialmente, serão descritas as informações dos autores, como quantidade e instituições. Em seguida serão apresentados os dados metodológicos com o tipo de pesquisa e análise de dados.

Com relação ao primeiro bloco de informações, observou-se que a quantidade de autores por artigo variou entre um e dois, com cinco artigos de um autor e quatro artigos de dois autores. Quanto às instituições e estados de origem, as representadas foram Universidade Federal de Pernambuco (Recife/PE), Universidade Estadual de Feira de Santana (Feira de Santana/BA), Universidade Estadual de Campinas (Campinas/SP), Universidade Luterana do Brasil (Pirassununga/SP), Universidade de São Paulo (São Paulo/SP).

Para a análise dos aspectos metodológicos dos artigos, investigou-se, inicialmente, se os trabalhos apresentavam o problema, os objetivos e a metodologia, pois esses elementos balizam toda a coleta e análise dos dados visando à consecução dos propósitos de uma pesquisa. A seguir, serão apresentados os objetivos dos artigos estudados. (Tabela 1). 
Tabela 1. Objetivos dos estudos analisados

\begin{tabular}{|c|c|c|}
\hline Categoria & Temas Indicativos & Frequencia \\
\hline Representações sociais & $\begin{array}{l}\text { Examinar a possível existência } \\
\text { de representações sociais de } \\
\text { afetividade nos professores de } \\
\text { ensino fundamental. }\end{array}$ & 1 \\
\hline Afetividade e Educação & $\begin{array}{l}\text { Analisar as características dos } \\
\text { professores, a falta de inter- } \\
\text { relação entre afetividade e } \\
\text { cognição e a insuficiência de } \\
\text { obras sobre a dimensão afetiva. }\end{array}$ & 1 \\
\hline Afetividade e Cognição & $\begin{array}{l}\text { Discutir a importância do estudo } \\
\text { dos teóricos: Piaget, Wallon } \\
\text { e vygotsky. Descrever práticas } \\
\text { pedagógicas desenvolvidas por } \\
\text { um professor em relação a } \\
\text { afetividade. Discutir afetividade e } \\
\text { cognição. }\end{array}$ & 5 \\
\hline Dimensão Afetiva & $\begin{array}{l}\text { Investigar como a postura do } \\
\text { professor, em sala de aula, tem } \\
\text { implicações sobre a experiência } \\
\text { de aprendizagem. Demonstrar } \\
\text { como os fatores afetivos se } \\
\text { apresentam na relação } \\
\text { professor-aluno. }\end{array}$ & 2 \\
\hline
\end{tabular}

A coluna "termos indicativos" exibe a forma com que o objetivo foi expresso no resumo. Quatro categorias puderam ser organizadas havendo uma concentração maior de artigos na categoria Afetividade e Cognição. Numa segunda análise foi feito $o$ agrupamento em três categorias dos tipos de pesquisa e métodos de análise adotados. As descrições de cada categoria bem como a frequência encontrada acerca dos tipos de pesquisa estão apresentadas na Tabela 2.

Tabela 2. Tipo de pesquisa e o método de análise adotado.

\begin{tabular}{lcc} 
Tipo & Análise & Frequência \\
\hline Pesquisa Bibliográfica & Fundamentação Teórica & 5 \\
$\begin{array}{l}\text { Pesquisa de Campo: Abordagem } \\
\text { Qualitativa }\end{array}$ & Análise de Conteúdo & 3 \\
$\begin{array}{l}\text { Pesquisa de Campo Mista: Abordagens } \\
\text { Qualitativa e Quantitativa }\end{array}$ & $\begin{array}{c}\text { Análise de Conteúdo e } \\
\text { Análise do Discurso }\end{array}$ & 1
\end{tabular}

Os dados visualizados na Tabela 2 apontam que a pesquisa bibliográfica foi a mais praticada. O mesmo pode ser afirmado em relação à análise de conteúdo. Embora o número de trabalhos a partir de pesquisas de campo qualitativas não tenha sido expressivo, os que foram encontrados adotam essa análise para discussão dos resultados. A respeito dos participantes, no total os estudos contaram com dados de 275 pessoas. Os dados coletados foram provenientes dos estados de São Paulo (5 artigos), Pernambuco (2 artigos) e Bahia (2 artigos). 


\section{DISCUSSÃO}

Considerando que o objetivo de estudos de levantamento de literatura é

mapear a produção científica em uma área ou tema específico, este artigo objetivou expor algumas características de pesquisas sobre afetividade na educação. Temáticas relativas à esse assunto foram presentes em todos os artigos citados. Com relação aos achados do presente estudo, os resultados mostraram que o termo que mais identificou os artigos foi Afetividade e Cognição, seguidas por Dimensão Afetiva, Representações Sociais e Afetividade e Educação.

O termo mais escolhido foi afetividade e cognição. Isto mostra que a afetividade vista como pouco importante depois do cogito cartesiano, ressurge, porque a razão não é capaz de aprender, de maneira globalizante, os fenômenos da realidade (CAPRA, 1996).

Wallon (2007) situa a noção de pessoa como o conjunto funcional resultante da integração de suas dimensões, e cujo processo de desenvolvimento ocorre na integração do orgânico com o meio, que em sua teoria é sempre predominantemente social. O desenvolvimento da pessoa como um ser completo não ocorre de forma linear e contínua, mas apresenta movimentos que implicam integração, conflitos e alternâncias na predominância dos conjuntos funcionais. No que diz respeito à afetividade e cognição, esses conjuntos revezam-se, em termos de prevalência, ao longo dos estágios de desenvolvimento.Afetividade e inteligência são inseparáveis e se integram.

Segundo Vigotsky, na interação social se constroe o conhecimento. O papel do outro é fundamental. Toda aprendizagem está impregnada de afetividade. Foi observado com a leitura dos artigos que a afetividade está sempre permeando as relações.
O número de obras sobre afetividade ainda é bem reduzido e a necessidade de desenvolver, nos professores, a dimensão afetiva na relação educativa é claramente necessária.

\section{CONCLUSÃO}

Nos dias de hoje a educação é uma ação complexa. Ela exige dos professores muito mais que o domínio dos conteúdos. Os professores precisam ter a capacidade de motivar seus alunos, dar atenção as suas dificuldades e aos seus progressos, ter respeito pelas diferenças, dentre outros aspectos. Os sujeitos se envolvem no processo de ensino-aprendizagem e aprendem por meio das interações. O sucesso dessa construção vai depender da qualidade dessas relações. (LEITE, 2006).

A partir das leituras e do levantamento destes artigos foi possível perceber a presença da afetividade positiva nas pesquisas tanto nas relações professor e aluno quanto nas posturas dos professores pesquisados. Espera-se que, com esse artigo, se tenha contribuído para indicar caminhos futuros para pesquisas na área da afetividade na educação. O reconhecimento da importância da afetividade e de suas áreas de atuação na sociedade passa pela ciência, principalmente quando esta consegue identificar lacunas a serem preenchidas a partir de demandas sociais. Gestores e professores formadores precisam discutir sobre o equilíbrio da dimensão cognitiva e afetiva na relação educativa.

\section{REFERÊNCIAS}

ANTUNES, C. Alfabetização emocional: novas estratégias. 13. ed. Petrópolis: Vozes, 2008.

CAPRA, F. A teia da vida uma compreensão científica dos sistemas vivos. São Paulo: Cultrix, 1996

FERREIRA, A.L. Do entre-deux de MerleauPonty à atenção consciente do budismo e da abordagem transpessoal: análise de uma 
experiência de formação integral. 2007. 449 f. Tese (Doutorado em Educação) - Pós-graduação em Educação, Universidade Federal de Pernambuco, Recife.

GOTTMAN, J.; DECLAIRE, J. Inteligência Emocional. 34. ed. Rio de Janeiro: Objetiva, 1997.

LEITE, S. A. da S. Dimensões afetivas na relação professor-aluno In: TASSONI, E. C. M. A afetividade em sala de aula: as condições de ensino e a mediação do professor. São Paulo: Casa do Psicólogo, 2006. p. 47-74.

RIBEIRO, M.; JUTRAS, F.; LOUIS, R. Análise das representações sociais da afetividade na relação educativa. Psic. da Ed., São Paulo, v. 20, , p. 3154, 2005. Disponível em: <http//pepsic.bvspsi.org.br/pdf/psie/v20/v20 a 03. Pdf>. Acesso em: 04 jun. 2012.

SILVA, J. B. C.; SCHNEIDER, E. J. Aspectos socioafetivos do processo de ensino e aprendizagem. Revista de divulgação técnico- científica do ICPG, v. 3, n. 11, jul.-dez., 2007 Disponível em: $<$ http://www.scribd.com/doc/13243945/aspectossocio-afetivo-do-processo-ensino-aprendizagem >. Acesso em: 5 ago. 2012

SOUZA, L. M. A psicologia na formação do professor. In: WITTER, G. P. Psicologia e Educação: professor, ensino e aprendizagem. São Paulo: Alínea, 2004, p.11-39.

TASSONI, E. C. M. Afetividade e aprendizagem: A relação professor e aluno. Anuário 2000. GT Psicologia da Educação Amped, setembro, 2000.

VIGOTSKY, L. S. O desenvolvimento psicológico na infância. São Paulo: Martins Fontes, 1999.

VYGOTSKY, L. S. (1994) A formação social da mente. São Paulo: Martins Fontes. 2002

WALLON, H. A Evolução Psicológica da Criança. São Paulo: Martins Fontes, 2007. 